\title{
What is the FDI World
}

\section{Dental Federation?}

For many in dentistry the letters FDI are familiar but not so familiar that they are able to explain what they mean, or indeed what the organisation stands for. On the eve of the FDI's Annual Congress in Montreal, and the BDA's support for John Hunt as the President-Elect, we take a look at the organisation and its aims.

The Fédération Dentaire Internationale (FDI) World Dental Federation is a federation of national dental associations and organisations whose main aims are to:

- Bring together the world of dentistry

- Represent the dental profession of the world

- Stimulate and facilitate the exchange of information across all borders with the aim of optimal oral health for all people.

These high ideals originated when the FDI was formed in the year 1900 in Paris, hence the original French name, making the Federation the second oldest international medical organisation after the Red Cross.

The FDI currently has over 120 national dental associations as members (including the BDA) and since all members of member associations are also deemed individual members, the organisation can legitimately claim to represent over 900,000 dentists worldwide.

\section{ORAL HEALTH FOR ALL}

With its mission statement including it being the worldwide voice of dentistry, the FDI aims to be authoritative, professional and independent thereby enabling it to promote optimal oral and general health for all peoples. To this end it includes scientific elements within its organisation as well as the increasingly high profile World Dental Development Fund, which supports oral health development projects around the globe.

Due to be launched at the Montreal Congress is a new 'Friends of the FDI' scheme, established to fill a void that has existed since the original FDI Individual Membership scheme was abolished some years ago. Many individuals have indicated their desire to be involved in the FDI's activities in a closer way than is presently possible. One of the purposes of the Friends scheme therefore is to provide interested individuals with a means through which they can contribute to the development of dentistry and oral health and be kept informed of how their donations are being utilised.

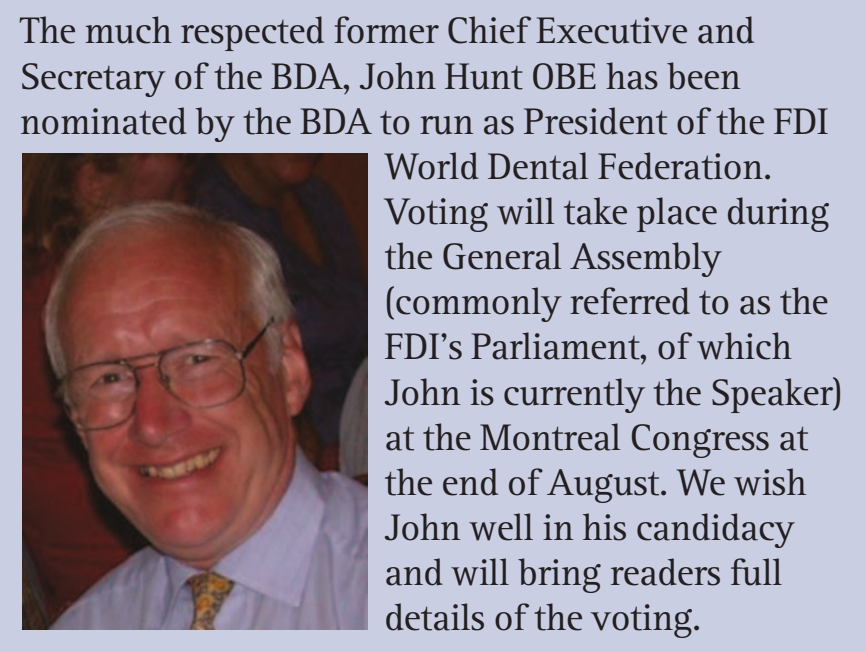

MONTREAL CONGRESS - STILL TIME TO REGISTER There is no better way to discover what the FDI is about than to visit an Annual World Dental Congress. Organised on a grand scale and in a different location in succeeding years, they attract thousands (sometimes tens of thousands depending on the venue) of dentists and team members from all over the world. The events include scientific and clinical programmes, business meetings of international and regional societies, a full social programme as well as preand post-Congress tours and holidays. For full details of this year's Montreal Congress (24-27 August 2005) please visit the FDI website on www.fdiworldental.org and click on the Congress button.

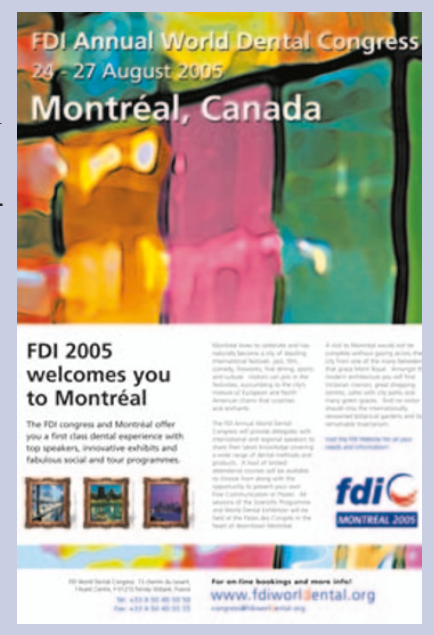

Future Congresses include: Shenzhen, China (22-25 September 2006) and Dubai (24-27 October 2007). 